\title{
Jesper Aastrup
}

Center for Retail Studies, Department of Marketing

Copenhagen Business School

DK-2000 Frederiksberg, Denmark

Tel: +4538152931; Fax: +4538152101

E-mail: jesper.aastrup@cbs.dk

\section{Herbert Kotzab}

Department of Operations Management

Copenhagen Business School

DK-2000 Frederiksberg, Denmark

Tel: +4538152450; Fax: +4538152440

E-mail: hk.om@cbs.dk

\section{David B. Grant}

Logistics Research Centre, School of Management and Languages

Heriot-Watt University

Edinburgh UK, EH14 4AS

Tel: +441314513527; Fax: +441314518336

E-mail: d.b.grant@hw.ac.uk.

\section{Christoph Teller}

Institute of Retailing and Marketing

Vienna University of Economics and Business Administration

A-1090 Vienna, Austria

Tel: +431313364622; Fax: +43131336717

Email: christoph.teller@wu-wien.ac.at

\section{Mogens Bjerre}

Center for Retail Studies, Department of Marketing

Copenhagen Business School

2000 Frederiksberg, Denmark

Tel: +4538152122; Fax: +4538152101

E-mail: mb.marktg@cbs.dk

Paper for International Journal of Retail and Distribution Management

Submitted March 2007

Revision May 2007

Acceptance June 2007 


\section{A Model for Structuring Efficient Consumer Response Measures}

\section{Authors’ Biographies}

Dr. Jesper Aastrup is Assistant Professor in the Centre for Retail Studies, Department of Marketing, Copenhagen Business School, Denmark. His research focuses on grocery retailing, supplier-retailer relationships, category management, value creation, and efficient consumer response (ECR).

Professor Herbert Kotzab is Professor in the Department of Operations Management at Copenhagen Business School, Denmark. His research focuses on supply chain management theory and practice, marketing and logistics, category management, and efficient consumer response (ECR). In 1998 he was visiting scholar at the Center for Transportation Studies at the Massachusetts Institute of Technology.

Dr. David B. Grant is Senior Lecturer in the Logistics Research Centre, Heriot-Watt University, Edinburgh UK. His research focuses on customer service and satisfaction, service quality, logistics and supply chain relationships, SME logistics, integration of logistics and marketing, and research methodologies and techniques. His $\mathrm{PhD}$ investigated $\mathrm{UK}$ food processing customer service, satisfaction and service quality and received the James Cooper Memorial Cup PhD Award from the Chartered Institute of Logistics and Transport (UK).

Dr. Christoph Teller is Assistant Professor in the Department of Retailing and Marketing, Vienna University of Economics and Business Administration, Austria. His research focuses on store and agglomeration format patronage, in-store logistics, distance retailing and supplier-retailer relationships.

Dr. Mogens Bjerre is Associate Professor and Director of the Centre for Retail Studies, Department of Marketing, Copenhagen Business School, Denmark. His research focuses on retailing, retailer positioning and branding, private labels, trade marketing, customer relationship management, key account management and efficient consumer response (ECR).

\section{Corresponding Author:}

Dr. Jesper Aastrup at jesper.aastrup@cbs.dk. 


\section{A Model for Structuring Efficient Consumer Response Measures}

\section{Structured Abstract}

Purpose: The purpose of this paper is to propose a model which structures and links different types of efficient consumer response (ECR) measures; it does so by considering the use of both quantitative or 'hard' and qualitative or 'soft' measures in ECR, emphasizing the importance and causal role of 'soft' measures throughout the ECR process.

Methodology/Approach: This paper reviews the ECR and performance measurement literature and proposes a model that explains linkages from intra-organizational, interorganizational and industry prerequisites through ECR activities to ECR outcomes; and highlights the role of performance, behavioural, attitude and capability measures. Two extant studies from Austria and Denmark are examined in the context of the model to exemplify some of its features.

Research limitations/implications: The proposed model is presented for primarily future investigation; thus there is no empirical study in this paper other than a comparison of the two extant studies to support some constructs and variables. However, the model represents a structure that can guide future research on more specific ECR elements.

Practical implications: The model makes a practical contribution by providing a structure from which measurement or scorecard systems can be established.

Originality/value of the paper: The model makes a theoretical contribution by providing an overall structure to link different areas of ECR research such as barriers for ECR implementation, and specific ECR concepts, activities, and their outcomes.

Keywords: ECR, Logistics measures, Soft measures, Austria, Denmark

Paper Category: Conceptual Paper and General Review 


\section{A Model for Structuring Efficient Consumer Response Measures}

\section{Introduction}

Channels of distribution can be organized within a vertical integration continuum between make, i.e. vertical integration, and buy, i.e. classical market contracting (Coughlan et al., 2006). In the grocery industry, distribution channel manufacturers and retailers have commonly decided to organize their distribution channel based on a hybrid or relational governance structure between make and buy. This channel strategy is known as efficient consumer response (ECR).

ECR can so be seen as a quasi-vertical type of integration between retailers and manufacturers to fulfil consumer needs better, faster and at less cost (ECR Europe, 1996). ECR was designed to develop competitiveness in grocery supply chains and it promises major benefits in terms of lower total inventories and costs, increased value created for consumers in terms of choice and quality of products, enhanced supplier-retailer relationships, more successful development of new consumer-driven products, a more seamless product delivery flow and reduced bull-whip effects (Salmon, 1993; Kotzab, 1999; Whipple et al. 1999; Lothia et al., 2004; Stewart, 1999; Lee et al., 1997).

The overall goal of an ECR-partnership is to simplify market flows between actors and ECR can be characterized as a streamlined distribution channel partnership (Buzzell and Ortmeyer, 1995). Empirical evidence from the UK shows that suppliers and retailers gain benefits in logistics and in sales related fields from such closer collaborative practices (Corsten and Kumar, 2005). Corsten and Hatch (2001) have also demonstrated that ECR can account for $37 \%$ of total channel performance.

Although the ideals of ECR and its expected benefits have been known since the beginning of the 1990s (Salmon, 1993), the ECR-concept is still not as widespread in practice as one might expect. Most firms in the grocery sector work with ECR and ECR-related concepts and activities. More often though the total ECR concept is not applied as either certain ECR elements are not considered or others are only partly implemented. A truly ECR-organized distribution channel is rarely recognized. 
The UK leads the way in European ECR implementation due to ECR UK being integrated with, and supported by the UK's IGD, formerly the Institute of Grocery Distribution. Also, in order to improve operational efficiencies, UK grocery retailers have streamlined their supply chains. From centralization of distribution in the 1980s companies began to integrate primary and secondary distribution to reduce lead times and take inventory out of the retail supply chain. In the 1990s/early 2000s Fernie and Sparks (2004) claimed that the UK had one of the most efficient grocery supply chains in the world. And yet, even the UK's use of ECR is not without its flaws regarding collaboration and relationships between suppliers and retailers (Fernie and McKinnon, 2003; Grant, 2005).

Research has documented that one reason for the low degree of ECR application can be found in certain implementation hurdles and disappointing results at an early stage of implementation (Whipple et al., 1999; Kotzab, 2000; Borchert, 2002; Lothia et al., 2004). These findings indicate that a focus on the outcome dimensions of ECR has retarded the development of ECR partnerships as expected.

Outcomes are usually measured by 'hard' measures such as the number of electronic data interchange (EDI) standard messages or lower out-of-stock (OOS) values. However, we consider that implementation can also be input-driven since relational governance structures require specific cooperative attitudes from all actors. These aspects can be measured with 'soft' measures such as capability, interaction or attitudes; see for example Lothia et al. (2004) or Borchert (2002).

The purpose of this paper is to propose a model which structures and links different types of ECR measures; a number of EDI standard messages is hardly an aim in itself but a means towards an end such as reduced administrative costs and more reliable order procedures. Based on work by Kotzab and Teller (2003) the model emphasises the importance and structure of such 'soft' measures in relation to the implementation of ECR elements between retailers and suppliers. We also consider there are several challenges for ECR implementation that require consideration of 'soft' measures.

We first present ECR elements and their underlying prerequisites. Then, we discuss the role of 'hard' and 'soft' measures in supply chains; emphasising different areas of measures from a global ECR scorecard and the literature on implementation barriers. Based on these 
discussions the fourth section will propose a model that structures and links different types of ECR measures, and the logic of this model will be exemplified in the fifth section based on insights from Danish and Austrian studies. Finally, we address implications for research and management.

\section{ECR Standards, Processes and Prerequisites}

The concept of ECR was introduced in the beginning of the 1990's by the US-based Food Marketing Institute (FMI). The simple message of ECR is to organise the entire grocery supply chain in a holistic way by implementing strategic alliances between involved actors which ensure a profitable situation for every single member of the chain despite stagnant markets; i.e. a win/win/win situation. Such cooperative management increases total channel performance as compared to managing the channel in an isolated way such as through pure market exchange (Whipple et al., 1999, Brown and Bukovinsky, 2001). Firms therefore need to re-think their partnerships and close the gap from total mistrust to total partnerships and take into account 'soft' organizational and cultural issues (Zairi, 1998; Lothia et al., 2004). Successful implementation of such measures should enable firms to achieve supply chain excellence.

ECR is a consensus-based or hybrid-integrative channel cooperation structure, see for example Whipple et al. (1999) or Heide (1994), as independent channel participants recognize that they gain certain rewards while setting up norms and standards that commit organizations to closer channel relationships. This alliance then transforms channel relationships from winlose into win-win (Heide, 1994).

The ECR-concept suggests integrating specific business functions between retailers and suppliers and operating the business based on specific processes such as category management, continuous replenishment programs (CRP), cross docking, collaborative planning, forecasting and replenishment (CPFR), efficient unit load (EUL), and standards for item identification and communication in supply chains. (ECR-Austria, 2004; Glavanovits and Kotzab, 2002).

Figure 1 shows the distinction between supply side and demand side, as well as between processes and standards (ECR-Austria, 2000). Both supply and demand sides include 'involved' departments, e.g. procurement, logistics, marketing and sales, at both retailer and 
manufacturer levels. Processes and standards represent the content of ECR and the way business should be performed in channels of distribution (Alvarado and Kotzab, 2001, ECREurope, 2002).

\section{Insert Figure 1 about here}

Corsten (2000) distinguishes between three forms of ECR which reflect different levels of interdependence and levels of coordination between the involved members. The first stage, industry ECR, refers to the adaptation of common standards, such as European article number (EAN) codes, electronic data interchange (EDI) standards, and certified pools for master data, in order to gain critical mass. The implementation of specific processes between several channel actors takes place at the next level. These processes, e.g. cross-docking, are based on implemented standards and norms or network ECR. The final stage is the so-called partnership ECR where more sophisticated collaborative processes, e.g. category management, are executed in dyadic partnerships. The Corsten approach includes an implicit logic of having implemented certain standards on a broad level in the total channel. Certain actors then have the capabilities to transform these standards into processes and only selected channel players are able to perform ECR on the highest level.

While Figure 1 presents an overview of different concepts of ECR, Figure 2 illustrates ECR as a value-delivery system (Kotzab and Bjerre, 2005). Based on this perspective, we propose the following linkage in the ECR concept: ultimate ECR outcomes of reduced costs, more satisfied customers, etc. are the result of certain activities in the retail system of structures, processes and management components. For example, an outcome variable of an improved OOS situation results from sharing of zero-sales statistics between store, distribution centre and supplier. Such activities however necessitate certain prerequisites, e.g. a willingness to share sensitive information. We argue this three-level linkage is necessary and applicable for discussing a structure of ECR-related hard and soft measures.

\section{Insert Figure 2 about here}

\section{Measures of Performance, Scorecard and Prerequisites}

Conventional literature regarding supply chain performance measures focus on primarily 'hard' measures applicable to a focal firm. Such measures typically include costs, lead times, 
and service levels (Caplice and Sheffi, 1994, 1995; Stewart, 1995; Supply Chain Council, 2004).

Few contributions have considered 'soft' supply chain performance measures, i.e. measures with a perceptual or behavioural content. Chow et al. (1994) distinguished between 'hard' and 'soft' measures in their literature review and recommended more use of qualitative measures, but they concluded there are large differences in definitions and measures that preclude any consensus. These soft measures are important as performance measures, e.g. customer satisfaction, but are even more important when addressing measures related to processes and prerequisites.

Based on Figure 2 there is a distinction to the 'hard' and 'soft' measures discussed in the literature. Discussion of measures logically emphasises performance measures, i.e. the outcome variables in Figure 2. These can be 'hard' such as profits or costs as well as 'soft' such as customer satisfaction and loyalty. Input measures for ECR prerequisites, e.g. attitudes towards cooperation, and ECR components or processes, e.g. the degree of point-of-sale data sharing for replenishment purposes, can be explicitly developed, but more in the sense of success factors or scorecard measures. Hence, we argue for a distinction between performance measures, process/scorecard measures and prerequisite measures.

When it comes to process measures we need to look at measures of behavioural content. An extensive ECR scorecard is available from the Global Commerce Initiative and may be viewed at www.globalscorecard.net. In this context the scorecard represents a well-developed measure system based on behavioural measures, i.e. 'soft' measures, as it measures actual practices and behaviours through scales ending at the ideal or best practice; see Appendix 1 for the types of measures from the scorecard regarding CPFR.

Meffert (2001) refers to internal and collaborative 'hard' and 'soft' success factors that are responsible for receiving the best results out of ECR. While 'hard' factors describe the technical resources, e.g. information technology resources, organizational prerequisites, and company specific infrastructure, 'soft' factors refer mainly to attitudinal aspects, e.g. commitment, readiness for change, leadership, readiness for collaboration, and motivation. Research indicates that implementation of ECR tends to represent an '80-20' rule-of-thumb 
whereby 'soft' factors count for $80 \%$ and 'hard' factors for $20 \%$ of the success but refer to prerequisite measures (Meffert, 2001; Andraski, 1998).

These are also dealt with in research on implementation barriers (Lothia et al, 2004; Kurnia and Johnston, 2001, 2003; Borchert, 2002; Dussart, 1998; Gruen and Shah, 2000). We argue these implementation barriers in the literature can be summarised as follows:

1) Certain barriers relate to the concept of ECR, i.e. initial investments and implementation costs, the need for critical mass, and the lack of standards and performance measures.

2) Other barriers relate to the capabilities and commitment of the involved firms, i.e. technical capabilities and expert skills, the adequate organizational skills and orientation, and the necessary support from top-management.

3) One barrier relates to a necessary collaborative orientation, i.e. attitudes towards information sharing, the organizational institutionalization of interfaces, informal contacts, integration of companies in the value chain, exploitation of power, lack of trust, and the unbalanced division of benefits and risks.

4) Finally, another barrier refers to what Lothia et al (2004) and Kurnia and Johnston (2003) have identified as lack of understanding of ECR benefits, or in the terminology from Gruen and Shah (2000) system trust, i.e. the benefits perceived by the involved parties.

The scope of these barriers suggests that the operationalization of implementation status and/or prerequisites should include not only quantitative or 'hard' measures but also qualitative or 'soft' measures. Otherwise, the 'soft' side of channel collaboration, which also contributes to success and excellence in supply chain partnering, would be neglected.

\section{A Proposed Model for Structuring ECR Measures}

Based on the foregoing discussions we propose a model as shown in Figure 3 to capture the overall linked structure and content of ECR measures. This model draws on the basic structure of the Kotzab and Bjerre (2005) model in Figure 2; while its content is based on business processes of the ECR-Austria (2000) model in Figure 1, Corsten's (2000) distinction between industry, network and partnership ECR as well as the implementation barriers identified from the literature. 


\section{Insert Figure 3 about here}

The outcome of any ECR-related activity should be evaluated in relation to one or several performance measures, depending on the ECR activity. For each ECR concept activity certain outcome measures must be identified as the ultimate aim. Performance measures related to supply chain cost levels, reliability or customer satisfaction are all considered outcome measures in our proposed model whether labelled 'hard' or 'soft' (Meffert, 2001; Chow et al, 1994; Caplice and Sheffi, 1995). We argue that outcome measures from ECR activities can be demand-related and supply-related.

Demand- related can be grouped into sales/store related measures, e.g. category sales development, profits per square metre, or store sales efficiency, and consumer/shopper related measures, e.g. satisfaction measures. Appropriate demand-related measures to emphasise will depend on category characteristics, strategy, etc.

Supply-related measures can be grouped into logistics related costs measures, e.g. inventory levels or distributions costs, logistics related reliability measures, e.g. service levels, on-shelfavailability, or production reliability, and administrative accuracy measures, e.g. invoice accuracy or master data precision.

These performance measures are not produced by trust or a willingness to cooperate but are the result of extant intra- and inter-organizational activities such CPFR, EUL, and category management. Other activities are only partly implemented compared to ideals but are all captured by behavioural measures in our proposed model.

The distinction between application of standards and processes of category management and efficient replenishment is taken from ECR-Austria (2000). We believe the ECR global scorecard to be the most extensive measurement system available, representing 45 behavioural measures across different aspects of ECR. Each behavioural measure addresses activities performed on a five point scale rather than a specific concept; again see Appendix 1 regarding the CPFR questions of the scorecard. What the scorecard cannot do in relation to our proposed model is to distinguish sharply between prerequisites and ECR activities. 
Whereas trust and willingness to cooperate do not produce ECR outcomes in our proposed model, they are important prerequisites for many ECR activities, e.g. joint work between suppliers and retailers in order to improve and evaluate forecast procedures. Hence, in line with the Kotzab and Bjerre (2005) model we have included prerequisites. These are dealt with in the literature typically as implementation barriers or reasons for non-implementation.

Based on the barriers above identified from the literature we distinguish between industry prerequisites and prerequisites attached to the actors involved, i.e. typically the retailer and supplier, and their relationship. This distinction also corresponds with Corsten's (2000) distinction between industry ECR, network ECR and partnership ECR. The types of measures discussed in the literature regarding implementation barriers are numerous, but may be categorized as: 1) attitudinal measures, e.g. attitudes or perceptions towards a specific ECR partner, towards the benefits from sharing information, towards the concept of ECR, or towards the fairness of how benefits and risks are shared, and 2) capability measures, e.g. suppliers' consumer insights for creating category value, technical skills in relation to EDI exchange, or issues regarding necessary organizational commitments and orientations.

Industry level prerequisites include the following issues:

- implementation barriers on the availability of standards and tools;

- the existence of critical mass as well as norms; and

- conventions on how to cooperate on ECR activities.

Having comprised the most crucial 'soft' and 'hard' measures to operationalize ECR related prerequisites or input variables, activities, and prospective benefits from such collaborative partnerships, we now present empirical insights from two generic measurement approaches applied in two national ECR movements.

\section{Exploratory Empirical Insights - Examples from Austria and Denmark}

We examined our proposed model in the context of two independent and mutually exclusive studies in Austria and Denmark. We recognize this explorative examination does not provide rigorous application of the model and thus lacks some validity and generalizability. Nevertheless, the examination does highlight and support certain themes related to the model. 
In the Austrian study of ECR implementation the emphasis was on the intra- and interorganizational prerequisites of different types of ECR activities. Questionnaires were sent to 150 key informants within the 72 member firms of ECR-Austria. The questionnaire had 39 closed and open questions within four sections: descriptive and demographic statistics, general implementation of ECR, general success factors and pitfalls of ECR, and supply side and demand side issues. The survey was sent with a letter of introduction noting that the president of ECR-Austria endorsed the research. Forty-five responses from 45 firms were received for response rates of $30 \%$ from informants and $63 \%$ from member firms.

Respondents were asked a number of statements using a six point Likert scale with anchors of 'totally agree' and 'totally disagree' to investigate the notion of 'hard' and 'soft' intraorganizational and inter-organizational prerequisites using terminology from Meffert (2001), and which address prerequisites of ECR activities in our proposed model. Notwithstanding the high response rate from member firms the low number of actual responses did not lend itself to deeper statistical analysis. Table 1 shows the means and standard deviations.

\section{Insert Table 1 about here}

Respondents largely agreed they have highly committed top management, and informed people and even involved lower level management regarding internal planning and implementation of ECR (means all less than 3.5). Respondents also largely disagreed on internal execution factors; this question was formulated negatively. Hence, these intraorganizational factors do not seem to represent important barriers in this survey.

The strategic and tactical collaborative factors measure the inter-organizational prerequisites. Collaboration factors on a strategic level generally showed mean values closer to the neutral 3.5 value. There is commitment given, which is manifested in a definition of common goals and partnership commitment, however these measures do not show values as significant as the intra-organizational factors. The results of tactical collaborative factors also indicate more importance was attached to barriers related to inter-organizational prerequisites than intra-organizational prerequisites. It was largely perceived that partners profit more than the responding firm, and the perception of fair distribution of profits was quite neutral. 
Further, respondents were asked to provide comments about success factors and pitfalls related to ECR across the four areas of category management, efficient replenishment, EUL and EDI, thus linking inter-organizational and inter-organizational prerequisites to different types of ECR activities. The ranking of the most recurring success factors and pitfalls are summarized in Table 2. Evidently, 'soft' factors dominate both success factors and pitfalls as opposed to 'hard' factors. However, the findings also indicate the importance of intraorganizational prerequisites which dominate compared to the more inter-organizational prerequisites.

\section{Insert Table 2 about here}

Whereas the Austrian study emphasised measures on prerequisites, the Danish study was based on behavioural measures based on an application of the ECR global scorecard. The global scorecard is a 'Capability Assessment Tool' consisting of 45 questions/scores. These deal with the different ECR activities through behavioural measures, i.e. ECR activities from our proposed model, but also assess elements of ECR prerequisites, however less systematically and with much less depth than the Austrian methodology.

The scorecard includes 45 questions with ratings between 0 (= no implementation) to 4 (= full implementation) covering different and specific ECR activities. Each of the 45 questions is attached to a specific formulation that presents the minimum requirement for each score, e.g. the minimum requirement for scoring 2 on the question of collaborative forecasting (see Appendix 1).

These specific formulations were the result of interviewing 28 suppliers to Danish grocery retailers. Data were collected by face-to-face interviews with 3 or 4 persons from different departments of each company. The interviews took between 2-4 hours and each respondent firm 'scored' their trade with each of the four main retail groups that cover about $85 \%$ of grocery turnover in Denmark.

Each scorecard has the trade between a specific supplier and a specific retail group in a specific category as its unit of analysis. Hence, each interview resulted in more than one scorecard. A total of 166 'capability' scorecards were collected from these 28 suppliers 
(Aastrup et al., 2007). In this paper we focus on results from the 'capability' scorecard that allow a comparison of the four overall areas with the Austrian survey results (see Table 3).

\section{Insert Table 3 about here}

We have indicated the score at which collaboration, as an inter-organizational prerequisite, enters the scorecard content where relevant. For example, the question on collaborative forecasting activities across firm boundaries requires a limited degree from score 2. A more systematic collaborative forecast requires a score 3, while score 1 and below covers internal forecast practices. Hence, this gives insight on the share of scorecards indicating some level of collaboration.

The Danish grocery sector has widely implemented EDI standard messages for orders and invoices (92 \% at score two and above). On the other hand, the use of EDI standard messages for exchanging planning and forecasting data is very rare. The question on EUL contains elements of collaborative pilot processes from level 2. The results indicate that $65 \%$ of the scorecards have some level of cooperation with their trade partners in terms of harmonisation and integration on packaging issues. This shows that inter-organizational prerequisites are not considered an important barrier here.

Score two for the replenishment side generally indicates limited cooperation or pilot work, while score three and above requires more systematic cooperation. The first three questions indicate that more systematic collaboration is limited to $20-25 \%$ of the scorecards (scores 3 and 4), while score 2 covers pilot work, limited relationships and some data exchanged manually.

The Danish replenishment system is perceived by suppliers as very demand driven, however not very collaborative (Aastrup et al., 2007). Service levels are considered quite central in the trade between Danish suppliers and retailers. This is covered by the reliable distribution question that also shows the highest mean value on the replenishment questions.

The last two questions refer to CPFR and the scores show some sharing of plans, most often limited to the yearly negotiated terms of trade, but there is only rare interaction on the forecast process, thus underscoring the impression of lower replenishment related collaboration. 
The pattern on the demand side is more varied. The first two questions address more general collaboration as well as information sharing. About 40 and $30 \%$ respectively indicate close and systematic cooperation. The question on shopper targeting is quite illustrative. This is a highly strategic matter regarding which segments to target in stores. Only $12 \%$ of the scorecards report collaboration in this area. $55 \%$ in score 2 indicate that each party prioritize segments without coordination.

The scorecard also contains category management related questions on assortment, promotion and new product introductions. Assortment is addressed here but promotions and new product introductions show similar patterns. Assortment planning indicates that about $45 \%$ of the scorecards have a more systematic collaboration on this issue, whereas the issue of evaluation indicates less collaborative efforts.

Hence, more scorecards indicate closer demand side cooperation than supply side cooperation. However a large number still indicate only limited or even less cooperation. Many respondents stated that they are willing and capable of contributing in demand side collaboration but that the collaboration is determined by what the retailer perceives beneficial in relation to resources required. Thus, collaboration is a barrier and prerequisite not met, but underlying reasons might be system trust of retailers (Gruen and Shah, 2000).

In summary, both studies indicate a lack of collaboration as an important prerequisite and barrier to successful ECR implementation. Lack of system trust and other 'soft' intraorganizational factors appear also to be critical prerequisites. Since both approaches represent the state-of-the-art of endeavours to identify, operationalize and evaluate ECR activities the consequences for improvement and/or expansion based on the proposed model follow next.

\section{Conclusions and Implications}

A variety of different measures with varying roles of assumed causality are present in the ECR literature. This paper has discussed the issue of 'hard' and 'soft' measures and their different roles in ECR implementation based on extant models from several different literature sources. We have demonstrated that both types of measures are required for explaining ECR partnerships and developed a model to structure and visualize this phenomenon. The model proposes natural linkages from intra- and inter-organizational 
prerequisites through ECR activities to ECR outcomes. ECR outcomes can be captured by traditional performance measures that can be demand-related, e.g. sales or satisfaction, or supply-related, e.g. inventory costs or service levels. Measuring ECR activities will rely on behavioural measures and scorecard measures on EDI usage, sharing of forecasts etc. The model also emphasises prerequisites to be captured by measures on attitudes and capabilities.

The model and the related issue of hard and soft measures were explored using two different and mutually exclusive extant studies in Austria and Denmark. Similarities regarding issues of inter-organizational and intra-organizational prerequisites were found, but the two studies also demonstrated variety in the use of measures in ECR research. Thus, we found some support for our propositions in this model. However, we recognize that this simple analysis lacks some rigour and generalizability and thus recommend further research as outlined below to apply, refine and validate or refute this model.

The model proposed in this paper has potential implications for research and management. We believe the model makes a theoretical contribution in the sense that it provides a structure or orientation that links different areas of ECR research which use a variety of measures, e.g. research on implementation barriers, research on specific concepts and activities in ECR, and outcomes.

More specifically it opens up research opportunities on the importance of different elements in implementing and reaching the benefits and outcomes of ECR practices. We suggest the following questions as examples. Does the importance of prerequisites differ from implementing ECR standards, efficient replenishment and category management? What types of measures are important when implementing different types of ECR related activities? What are the outcomes in terms of performance measures from different ECR activities? Some of these linkages have been studied previously, while others are less rigorously dealt with.

We also believe this model represents a structure that can guide research on more specific ECR activities such as CPFR or OOS. The model provides a structure from which hypotheses can be formulated about relations between attitudinal, behavioural, capability and performance constructs in relation to a specific ECR element. Studying the prerequisites and outcomes of CPFR would require developing behavioural measures on the CPFR activities itself; it would require developing measures of attitudinal and capability elements; as well as 
relevant performance measures. OOS is basically a performance measure - what then are the necessary activities (behavioural measures) to approach and what are the underlying prerequisites (attitudinal measures) for e.g. sharing zero sales statistics? In that sense the model provides input to developing measures related to empirical research and a structure to developed empirical models for correlation or causal studies.

In relation to management and applicable tools for business the proposed model provides an explicit structure from which practically oriented measurement systems or scorecard systems can be established or adjusted. Both generic/global and more firm-specific instruments can benefit from pursuing this model's underlying structure in their development. The global ECR scorecard (www.globalscorecard.net) deals explicitly with performance measures, however it does not explain the linkages towards behavioural measures. The measures in the scorecard are not strictly behavioural measures; attitudinal and capability measures are inherent in the scores and hence the scorecard mixes different types of measures in the same question. In this sense the model provides a theoretical framework for developing more explicit and coherent business measurement tools that is more robust.

\section{References}

Aastrup, J., Weber, O.J. and Bjerre, M. (2007) ECR practices in Danish grocery sectors 2006, ECR Denmark.

Alvarado, U.Y. and Kotzab, H. (2001) Supply Chain Management: The Integration of Logistics in Marketing, Industrial Marketing Management, 30, 183-98.

Andraski, J. (1998) Leadership and the realization of supply chain collaboration, Journal of Business Logistics, 19 (2), 9-11.

Borchert, S. (2002) Implementation hurdles of ECR partnerships - the German food sector as an ECR case study, International Journal of Retail \& Distribution Management, 30 (7), 354-60.

Brown, T. and Bukovinsky, D. (2001) ECR and grocery retailing: An exploratory financial statement analysis, Journal of Business Logistics, 22 (2), 77-90.

Buzzell, R. and Ortmeyer, G. (1995) Channel partnerships streamline distribution, Sloan Management Review, 36 (3), 85-96.

Caplice, C. and Sheffi, Y. (1994) A Review and Evaluation of Logistics Metrics, The International Journal of Logistics Management, 5 (2), 11-28.

Caplice, C. and Sheffi, Y. (1995) A Review and Evaluation of Logistics Performance Measurement Systems, The International Journal of Logistics Management, 6 (1), 6174.

Chow, G., Heaver, T.D. and Henriksson, L.E. (1994) Logistics Performance: Definition and Measurement, International Journal of Physical Distribution \& Logistics Management, 24 (1), 17-28. 
Corsten, D. (2000) Standards, processes and capabilities - a new view on co-operation in the consumer goods system, Logistics Research Network 2001 Conference Proceedings, Hines P. (ed.), Cardiff, UK, 147-52.

Corsten, D. and Hatch, D. (2001) Implementation and Success of ECR in Europe, Presentation at the $6^{\text {th }}$ ECR Europe Conference, Glasgow UK, 15-17 May.

Corsten, D. and Kumar, N. (2005): Do suppliers benefit from collaborative relationships with large retailers? An empirical investigation of Efficient Consumer Response adoption, Journal of Marketing, 69 (3), 80-94.

Coughlan, A., Anderson, E., Stern, L. and El-Ansary, A. (2001) Marketing Channels, $6^{\text {th }}$ edition, Prentice Hall, Upper Saddle River.

Dussart, C. (1998) Category Management: Strengths, Limits and Developments, European Management Journal, 16 (1), 50-62.

ECR-Austria (2000): Efficient Consumer Response, http://www.edi.org/ecr/start.html, accessed May 27, 2000.

ECR-Austria (2004) Efficient Consumer Response, http://www.edi.org/ecr/, accessed July 2, 2004).

ECR-Europe (2002) Focus areas of ECR, http://www.ecrnet.org/ECR/, accessed September 17, 2002.

ECR-Europe (1996) European Value Chain Analysis - Final Report, ECR Europe, Switzerland.

Fernie, J. and Sparks, L. (2004) Logistics and Retail Management: Insights into Current Practice and Trends from Leading Experts, Kogan Page, London.

Fernie, J. and McKinnon, A.C. (2003) The grocery supply chain in the UK: improving efficiency in the logistics network, International Review of Retail, Distribution and Consumer Research, 13 (2), 161-74.

Glavanovits, H. and Kotzab, H. (2002) ECR Kompakt. Efficient Consumer Response Von der Theorie zur Praxis in Österreich, EAN-Österreich, Wien.

Grant, D.B. (2005) The Transaction - Relationship Dichotomy in Logistics and Supply Chain Management, Supply Chain Forum: An International Journal, 6 (2), 38-48.

Gruen, T.W. and Shah, R.H. (2000) Determinants and outcomes of plan objectivity and implementation in category management relationships. Journal of Retailing, 76 (4), 483-510.

Heide, J. (1994) Interorganizational governance in marketing channels, Journal of Marketing, 58 (1), 71-85.

Kotzab, H. and Bjerre, M. (eds.) (2005) Retailing in a SCM-perspective, Copenhagen Business School Press.

Kotzab, H. and Teller, C. (2003) Value-adding partnerships and co-opetition models in the grocery industry, International Journal of Physical Distribution \& Logistics Management, 33 (3), 268-81.

Kotzab, H. (1999) Improving supply chain performance by Efficient Consumer Response? A critical comparison of existing ECR-approaches, Journal of Business and Industrial Marketing, 14 (5/6), 364-77. 
Kotzab, H. (2000) Managing the Fast Moving Goods Supply Chain - Does Efficient Consumer Response Matter? in Proceedings of the Logistics Research Network $5^{\text {th }}$ Annual Conference, Cardiff Business School UK, 336-43.

Kurnia, S. and Johnston, R.B. (2001) Adoption of efficient consumer response: the issue of mutuality, Supply Chain Management: An International Journal, 6 (5), 230-41.

Kurnia, S. and Johnston, R.B. (2003) Adoption of efficient consumer response: key issues and challenges in Australia, Supply Chain Management: An International Journal, 8 (3), 251-62.

Lee, H.L., Padmanabhan, V. and Whang, S. (1997) The Bullwhip Effect in Supply Chains, Sloan Management Review, Spring, 93-102.

Lothia, R., Xie, T. and Subramaniam, R. (2004) Efficient Consumer Response in Japan. Industry concerns, current status, benefits, and barriers to implementation, Journal of Business Research, 57, 306-11.

Meffert, H. (2001) Optimierung von Wertschöpfungsketten, Münster, Germany, presentation material.

Salmon, K. (1993) Efficient Consumer Response: Enhancing Consumer Value in the Grocery Industry, Washington, FMI.

Stewart, G. (1995) Supply chain performance benchmarking study reveals keys to supply chain excellence, Logistics Information Management, 8 (2), 38-44.

Stewart, D. (1999) Beginning Again: Change and Renewal in Intellectual Communities, Journal of Marketing, 63 (4), 2-4.

Supply Chain Council (2004) Supply Chain Operations Reference model: Overview of SCOR Version 5.0, www.supply-chain.org.

Whipple, J.S., Frankel, R. and Anselmi, K. (1999) The Effect of Governance Structure on Performance: A Case Study of Efficient Consumer Response, Journal of Business Logistics, 20 (2), 43-62.

Zairi, M. (1998) Best practice in supply chain management: the experience of the retail sector, European Journal of Innovation Management, 1 (2), 59-66. 


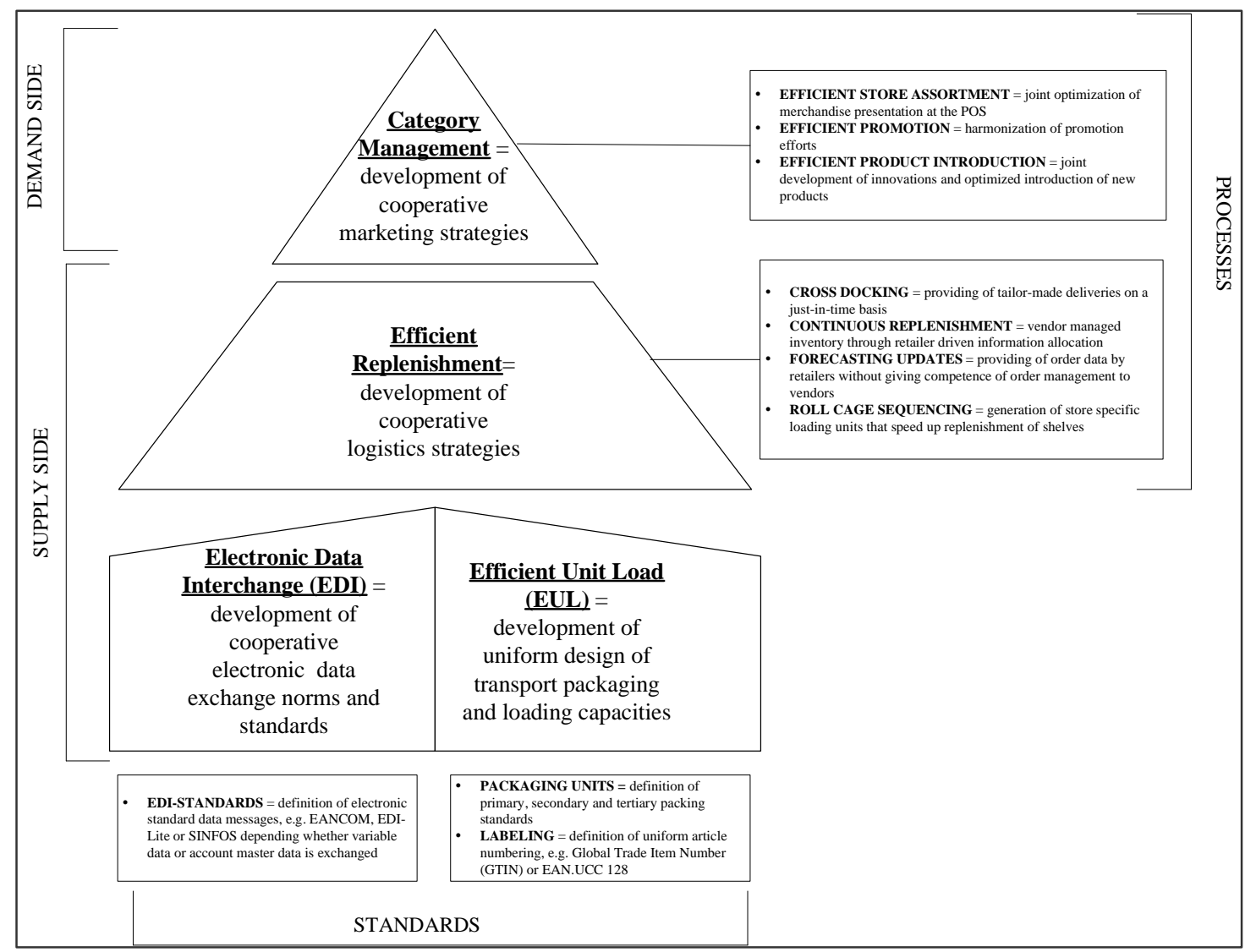

Figure 1: A generic efficient consumer response business process model (ECR-Austria, 2000). 


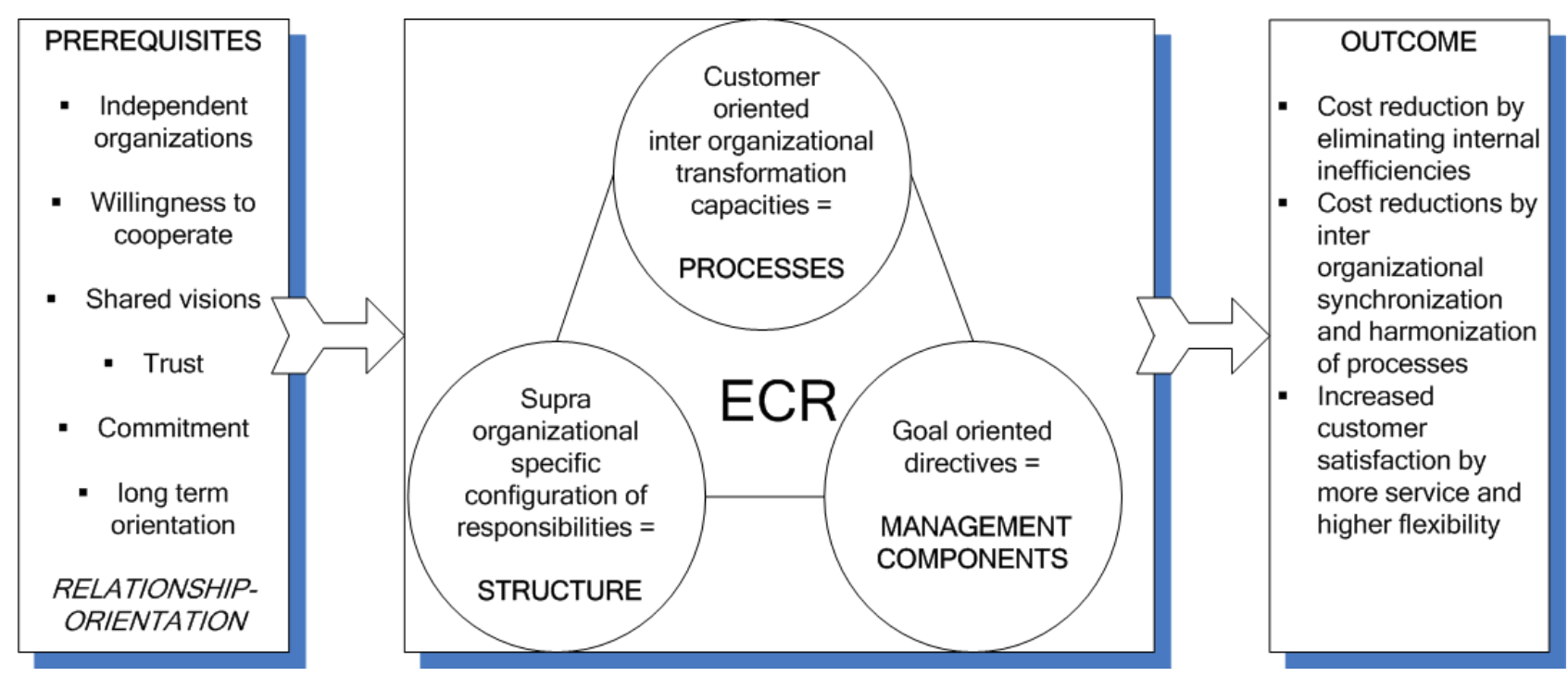

Figure 2: Efficient consumer response as value-delivery system (Kotzab and Bjerre, 2005) 


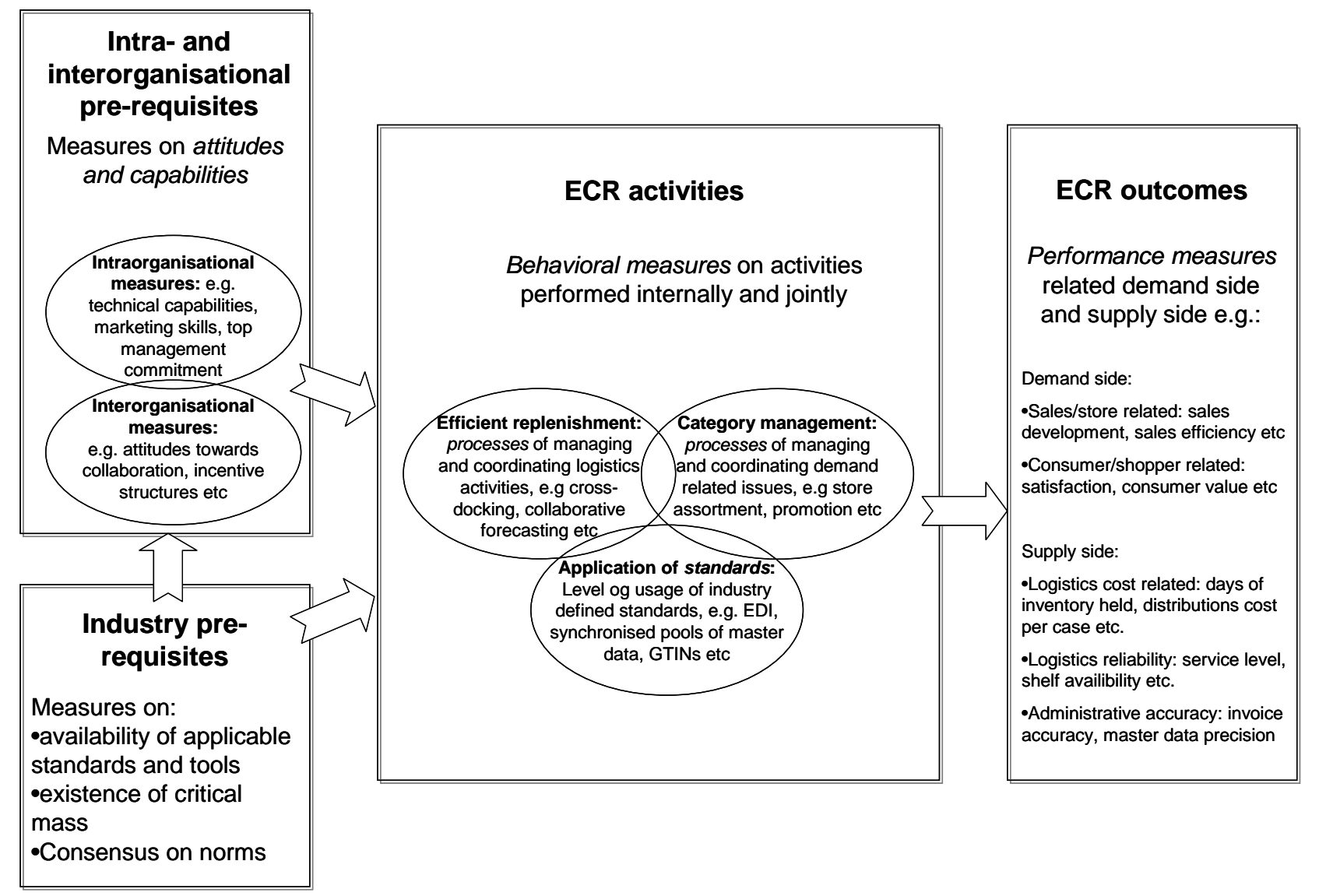

Figure 3: Structures of measures in Efficient Consumer Response 
Table 1. Soft' Factors related to ECR Implementation (1=totally agree, 6=totally disagree)

\begin{tabular}{|c|c|c|}
\hline & Mean & Std Dev \\
\hline \multicolumn{3}{|l|}{ Intraorganizational prerequisites - general attitudes towards ECR } \\
\hline ECR brought the expected advantage & 2.43 & .93 \\
\hline Our company will also gain from ECR in the future & 2.07 & .82 \\
\hline Employees have a positive attitude towards ECR & 2.59 & 1.21 \\
\hline ECR has lost importance in our company & 3.34 & 1.22 \\
\hline \multicolumn{3}{|l|}{ Intraorganizational prerequisites - internal planning factors } \\
\hline Top management shows interest in the implementation of ECR & 2.25 & 1.04 \\
\hline $\begin{array}{l}\text { All employees of the involved departments had been informed about the implementation } \\
\text { Before implementing we plan and define goals }\end{array}$ & & 1.34 \\
\hline \multirow[t]{2}{*}{ Employees of lower management levels are involved in the planning } & 2.27 & 1.25 \\
\hline & 2.50 & 1.32 \\
\hline \multicolumn{3}{|l|}{ Intraorganizational prerequisites - internal execution factors } \\
\hline The implementation of ECR conflicted with other internal goals & 3.63 & 1.45 \\
\hline The time pressure of the implementation was too high & 3.81 & 1.26 \\
\hline The pressure for results was too high & 4.07 & 1.16 \\
\hline The staff was not sufficiently qualified & 4.23 & 1.34 \\
\hline There was no control & 3.60 & 1.50 \\
\hline Top management showed no consequences & 4.05 & 1.54 \\
\hline There was no technical equipment & 3.79 & 1.55 \\
\hline The internal processes are not transparent & 4.44 & 1.32 \\
\hline The needed data was not available & 4.00 & 1.69 \\
\hline \multicolumn{3}{|l|}{ Interorganizational prerequisites - strategic collaborative factors } \\
\hline Our partner had the same expectations as we had & 3.14 & 1.34 \\
\hline Both sides had claimed for early results & 3.23 & 1.07 \\
\hline Both sides committed openly for the partnership & 2.88 & 1.26 \\
\hline Goals were set up in a collaborative manner & 2.91 & 1.19 \\
\hline We agreed on a common reporting system & 3.74 & 1.58 \\
\hline \multicolumn{3}{|l|}{ Interorganizational prerequisites - tactical collaborative factors } \\
\hline The compatibility of the standards was a pitfall & 2.90 & 1.33 \\
\hline Sharing the profits was fair & 3.46 & 1.17 \\
\hline Our partner has profited more than us & 2.40 & 1.15 \\
\hline The cooperation had positive effects for the price policy & 4.38 & 1.23 \\
\hline
\end{tabular}


Table 2. ECR-Specific Success Factors and Pitfalls

\begin{tabular}{|c|c|c|}
\hline ECR Area & Success Factors & Pitfalls \\
\hline Efficient Unit Load & $\begin{array}{l}\text { 1. Commitment of partners to apply the } \\
\text { standards } \\
\text { 2. Detailed planning and exact goals } \\
\text { 3. Coordination of internal goals with ECR- } \\
\text { goals }\end{array}$ & $\begin{array}{l}\text { 1. The rearrangement is heading for only } \\
\text { long-term orientation } \\
\text { 2. The rearrangement can be expensive } \\
\text { 3. Customer requirements might conflict } \\
\text { with standards }\end{array}$ \\
\hline $\begin{array}{l}\text { Electronic Data } \\
\text { Interchange }\end{array}$ & $\begin{array}{l}\text { 1. Commitment of partners to apply the } \\
\text { standards } \\
\text { 2. Detailed planning and exact goals } \\
\text { 3. Involvement of employees in the planning } \\
\text { phase }\end{array}$ & $\begin{array}{l}\text { 1. Inconsistent information about EDI } \\
\text { 2. Low innovation willingness } \\
\text { 3. No interest of top management }\end{array}$ \\
\hline Efficient Replenishment & $\begin{array}{l}\text { 1. Detailed planning and exact goals } \\
\text { 2. Commitment of partners to apply the } \\
\text { standards } \\
\text { 3. Coordination of internal goals with ECR- } \\
\text { goals }\end{array}$ & $\begin{array}{l}\text { 1. Low readiness for collaboration among } \\
\text { partners } \\
\text { 2. Large efforts to implement } \\
\text { 3. Lack of information at top } \\
\text { management level }\end{array}$ \\
\hline Category Management & $\begin{array}{l}\text { 1. Detailed planning and exact goals } \\
\text { 2. Employee training } \\
\text { 3. Information of employees }\end{array}$ & $\begin{array}{l}\text { 1. Low readiness for collaboration among } \\
\text { partners } \\
\text { 2. Large efforts to implement } \\
\text { 3. Lack of information at top } \\
\text { management level }\end{array}$ \\
\hline
\end{tabular}


Table 3. Results from Danish scorecard survey $(*=$ limited collaboration required, $* *=$ more systematic collaboration required)

\begin{tabular}{|c|c|c|c|c|c|c|c|}
\hline \multirow[t]{2}{*}{ ECR activities } & \multirow[t]{2}{*}{ Mean value } & \multirow{2}{*}{$\begin{array}{l}\text { Standard } \\
\text { deviation }\end{array}$} & \multicolumn{5}{|c|}{ Distribution of scores } \\
\hline & & & 0 & 1 & 2 & 3 & 4 \\
\hline \multicolumn{8}{|l|}{ EDI and EUL } \\
\hline Standard messages for supply & 2.7 & 1.1 & $2.0 \%$ & $6.0 \%$ & $48.7 \%$ & $6.7 \%$ & $36.7 \%$ \\
\hline $\begin{array}{l}\text { Standard messages for forecasting } \\
\text { and planning }\end{array}$ & 0.4 & 0.8 & $68.7 \%$ & $24.0 \%$ & $3.3 \%$ & $2.0 \%$ & $2.0 \%$ \\
\hline Efficient Unit Load & 2.2 & 1.4 & $15.7 \%$ & $18.7 \%$ & $24.7 \% *$ & $15.7 \%$ & $25.3 \%$ \\
\hline \multicolumn{8}{|l|}{ Efficient Replenishment } \\
\hline Strategic direction & 1.7 & 1.0 & $5.6 \%$ & $49.3 \%$ & $20.4 \% *$ & $19.7 \% * *$ & $4.9 \%$ \\
\hline People \& organisation & 1.8 & 0.8 & $5.3 \%$ & $32.7 \%$ & $41.4 \% *$ & $20.7 \% * *$ & $0 \%$ \\
\hline Information management & 1.9 & 0.9 & $13.3 \%$ & $7.3 \%$ & $59.3 \% *$ & $20.0 \% * *$ & $0 \%$ \\
\hline Reliable distribution & 2.6 & 1.1 & $6.0 \%$ & $7.3 \%$ & $34.7 \% *$ & $27.3 \% * *$ & $24.7 \%$ \\
\hline Collaborative planning & 1.5 & 0.7 & $4.7 \%$ & $46.7 \%$ & $41.3 \% *$ & $7.3 \% * *$ & $0.0 \%$ \\
\hline Collaborative forecasting & 1.2 & 0.5 & $5.3 \%$ & $76.6 \%$ & $15.3 \% *$ & $2.7 \% * *$ & $0.0 \%$ \\
\hline \multicolumn{8}{|l|}{ Demand management } \\
\hline People \& organisation & 2.2 & 0.8 & $0.7 \%$ & $20.4 \%$ & $36.6 \% *$ & $41.5 \% * *$ & $0.7 \%$ \\
\hline $\begin{array}{l}\text { Information technology } \\
\text { infrastructure }\end{array}$ & 2.0 & 1.2 & $16.0 \%$ & $21.4 \%$ & $24.7 \% *$ & $28.7 \% * *$ & $9.3 \%$ \\
\hline Shopper targeting & 1.8 & 0.8 & $10.0 \%$ & $21.3 \%$ & $56.7 \%$ & $12.0 \% * *$ & $0.0 \%$ \\
\hline Assortment planning & 2.4 & 0.9 & $2.7 \%$ & $18.7 \%$ & $31.3 \% *$ & $42.6 \% * *$ & $4.7 \%$ \\
\hline Assortment evaluation & 2.0 & 0.7 & $4.0 \%$ & $16.0 \%$ & $66.0 \% *$ & $14.0 \% * *$ & $0.0 \%$ \\
\hline
\end{tabular}


Appendix 1: CPFR example from global ECR scorecard (www.globalscorecard.net)

\section{GlobalECR Scorecard -- A Capab aihy Assessment Tool, Detailed des criptors}

Concept 11. Collaborative Planning \& Forecasting

Functions and trading partners working together to improve the planning of the supply chain through acc urate and timely information flow

\begin{tabular}{|c|c|c|c|}
\hline \multirow[b]{3}{*}{ Score } & \multirow[b]{3}{*}{ General Meaning } & \multicolumn{2}{|c|}{ Considerations } \\
\hline & & Collaborative Planning & Collab orative Forecasting \\
\hline & & 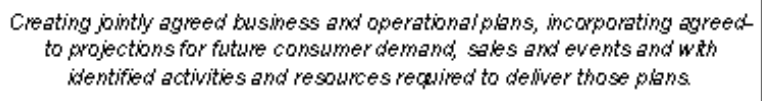 & $\begin{array}{c}\text { Common forecasting toois and processes are defined and implemented in } \\
\text { order to accurately predict antic pated levels and timing of consumer demand } \\
\text { adjusted for promotions and other events. }\end{array}$ \\
\hline 0 & Nothing pisnned & No joirt planning. Single company, departm ental plans exist. & Unreconciled multiple internal forecasts. \\
\hline 1 & $\begin{array}{l}\text { Pians agreed but have } \\
\text { not yet stanted } \\
\text { implementation }\end{array}$ & $\begin{array}{l}\text { A limited rumber of organisation departments or activities exchanging plans } \\
\text { between partners. Internally aligned plans exist. }\end{array}$ & $\begin{array}{l}\text { Internally driven channel, trading partner, category or product specific } \\
\text { forecasts. }\end{array}$ \\
\hline 2 & $\begin{array}{l}\text { Pibt tests being } \\
\text { conducted }\end{array}$ & $\begin{array}{l}\text { Plans that are exchanged are combined to fom a jointly agreed single plan. } \\
\text { Occasional joint review of the plan takes place. }\end{array}$ & $\begin{array}{l}\text { Rawdata is exchanged between trading partners and is adively incorporated } \\
\text { in forecasts. Processes exist to convert sales forecasts into order forecasts. } \\
\text { Accuracy of forecasts is measured. }\end{array}$ \\
\hline 3 & $\begin{array}{l}\text { Roilout of } \\
\text { impiementation stanted }\end{array}$ & $\begin{array}{l}\text { Agreed joint collaborative plans exjst across all processes for some key } \\
\text { trading partners. Some incorporation of other supply chain irtermediaries or }\end{array}$ & $\begin{array}{l}\text { Joint revewot data resuting in one agreed demand forecast which is } \\
\text { continuously updated for perfomance and acouracy. }\end{array}$ \\
\hline 4 & Fuly implemented & $\begin{array}{l}\text { Agreed joirt collaborative plans exist across all processes for all key trading } \\
\text { partners or trade channels. These incorporate an end to end supply chain } \\
\text { perspedive. Plans are frequently revieved and updated joirtly. }\end{array}$ & $\begin{array}{l}\text { Full collaborative forecasting, continuousy updated throughthe use of alert } \\
\text { m anagement techniques. Routine forecasts are automated enabling a foous } \\
\text { on joint event management. }\end{array}$ \\
\hline
\end{tabular}

